\title{
Organization of a Neurointensive Care Unit
}

\author{
Siddharth Chavali ${ }^{1, \oplus}$ Obaid A. Sidiqqi ${ }^{2}$ Girija P. Rath ${ }^{1, \Theta}$ \\ ${ }^{1}$ Department of Neuroanaesthesiology and Critical Care, All India \\ Institute of Medical Sciences (AIIMS), New Delhi, India \\ ${ }^{2}$ Department of Anaesthesiology, Aligarh Muslim University (AMU), \\ Aligarh, Uttar Pradesh, India
}

\begin{abstract}
Address for correspondence Girija P. Rath, MD, DM, Departmen of Neuroanaesthesiology and Critical Care, Neurosciences Centre, All India Institute of Medical Sciences (AlIMS), New Delhi 110029, India (e-mail: girijarath@yahoo.co.in).
\end{abstract}

Neuroanaesthesiol Crit Care 2019;6:182-186

\begin{abstract}
Keywords

- neurointensive care

- organization

- neurosurgery

- neurology

Although in its infancy as a specialty, neurocritical care is rapidly developing its own niche, with a wide profile of patients-both neurosurgical and those with neurological pathologies. Rapid advances in monitoring technology as well as surgical techniques have led to an increasing number of patients, often presenting with myriad concurrent illnesses, who could be best served if managed by specialist neurointensivists. Neurocritical care units are being developed as free-standing intensive care units in several tertiary care hospitals, and literature regarding their establishment and organization is scant, leading to questions regarding how best to utilize resources to gain maximum benefit. This review aims to outline the challenges that are likely to be faced during establishment of such a unit, and to identify certain issues that are specific to this specialty.
\end{abstract}

\section{Introduction}

The intensive care unit (ICU) is a specially designed section of the hospital where patients with acute life-threatening organ damage due to a disease or injury are given more effective and individualized treatment. ${ }^{1}$ During the past few decades, critical care medicine has evolved rapidly, due to therapeutic advances and a better understanding of the pathophysiology of various diseases. Neurocritical care (NCC) developed as a subspeciality of intensive care in the 1980s and has been dedicated to the management of critically ill neurologic patients. ${ }^{2}$ Over the years, the neurocritical care units (NCCUs) have evolved from larger multidisciplinary ICUs into freestanding units, not limited only to postoperative neurosurgical patients but also involving integrated management of other conditions of the central nervous system and their complications. ${ }^{3}$

The most commonly admitted patients in a NCCU are of stroke, head injury, brain tumors, and posthypoxic encephalopathy, whereas those with spinal cord injuries, status epilepticus, myasthenic crisis, Guillain-Barré syndrome, and neurological infections are relatively less common. ${ }^{4}$ There is compelling evidence to believe that such patients, when cared for in a specialist NCCU tend to have better outcomes than if treated in a multidisciplinary unit.
Interest in the potential benefits of NCCUs is increasing due to an increase in the volume of neurosurgery and rapid advancement of therapies for neurological and neurosurgical patients. This article aims to review the challenges specific to the establishment of an NCCU.

\section{Setting and Organization of a Neurocritical Care Unit}

An NCCU is considered to be a level III ICU, and should serve as a tertiary referral unit for intensive care patients, capable of providing comprehensive critical care for an extended period of time. The unit should preferably be a closed ICU headed by an intensivist who specializes in neurocritical care. The aim should be to provide long-term care of highest standards with defined protocols and policies. There should be a sufficient clinical workload and variety of patients to provide the requisite level of clinical expertise and education of staff, including trainees.

The different components in setting up and organizing an NCCU include:

\section{Policy and Guidelines}

The first and foremost thing is to develop a policy and define the guidelines for planning an NCCU. This can be

\section{Heeresterems \\ ()(1) $\Theta \circledast$}


accomplished by forming a committee comprising the medical superintendent, neurosurgeon, neurointensivists, neurologist, and nursing superintendent of the institute. Such a committee will appropriately define the critical care burden of the hospital, type and size of unit, appoint the unit in-charge, and form guidelines and policies. The unit should be assisted by an ethical committee which formulates policy for "do not resuscitate" orders, and organ donation.

\section{Designing the Neurocritical Care Unit}

In the era of modern medical practice, austerity measures can pose a real challenge to both clinicians and the administrative staff. Cost-effectiveness is now considered essential in almost all aspects of health care; however, there are certain prerequisites for the care of the neurologically injured patients that mandates a certain investment, both financially and in terms of staffing.

Ideally, a neurosciences unit should be either a standalone area or part of a multispecialty unit, centrally located and in close proximity to the emergency room, operation theaters, and trauma wards. An appropriately designed NCCU should provide adequate visualization of both patients and monitors, and facilitate staffing decisions based on patient acuity ( - Fig. 1). A circular layout of beds with a central nursing station might be the most ergonomic of designs. Corridors, lifts, and ramps should have a spacious and wide design to allow for safe and fast transport of critically ill patients.

A crucial inclusion for NCCUs is an area for family waiting; construction of designated "quiet rooms" or "grieving areas" must be a consideration during the planned construction of such a unit.

\section{Staffing and Associated Controversies}

Analogous to any other multidisciplinary ICU, staffing is the most important aspect of setting up a neuroscience unit. A typical recruitment list in India would include the following:

- Intensivist: Team leader, who should be a full timer and spend more than $50 \%$ of clinical time in the critical care unit.

- Residents/fellows: Postgraduates from anesthesiology, internal medicine, respiratory medicine, and other allied branches such as neurology or neurosurgery. The doctor to patient ratio should be 1:5.

- Nurses: A ratio of 1:1 is ideal for ventilated and multiorgan failure patients but should never be less than 2:3; a nurse:patient ratio of $1: 2$ to $1: 3$ should suffice for stable patients.

- Nutritionist

- Physiotherapist

- Technician

- Pharmacists: They may help with drug monitoring, and can improve adherence to clinical practice guidelines.

Recently, there has been some debate regarding the role of general intensivists versus superspeciality neurointensivists in the management of neurologically injured patients. ${ }^{5}$ All intensivists are presumed to have the knowledge of multisystem disturbances and requisite skills for advanced cardiac and hemodynamic support, as well as invasive hemodynamic monitoring. As such, both models may be appropriate, but physicians trained in neurointensive care may have an edge in managing the deranged cerebrovascular pathophysiology, and are also more accustomed to sensitive issues such as brain death and end-of-life care. Indeed, there is a growing body of literature to suggest that management of such patients in a special neurosciences unit may lead to significantly improved mortality and morbidity. ${ }^{6.7}$

Another issue of contention is whether ICUs should be "open" or "closed." ${ }^{, 9}$ In several countries, the intensivist

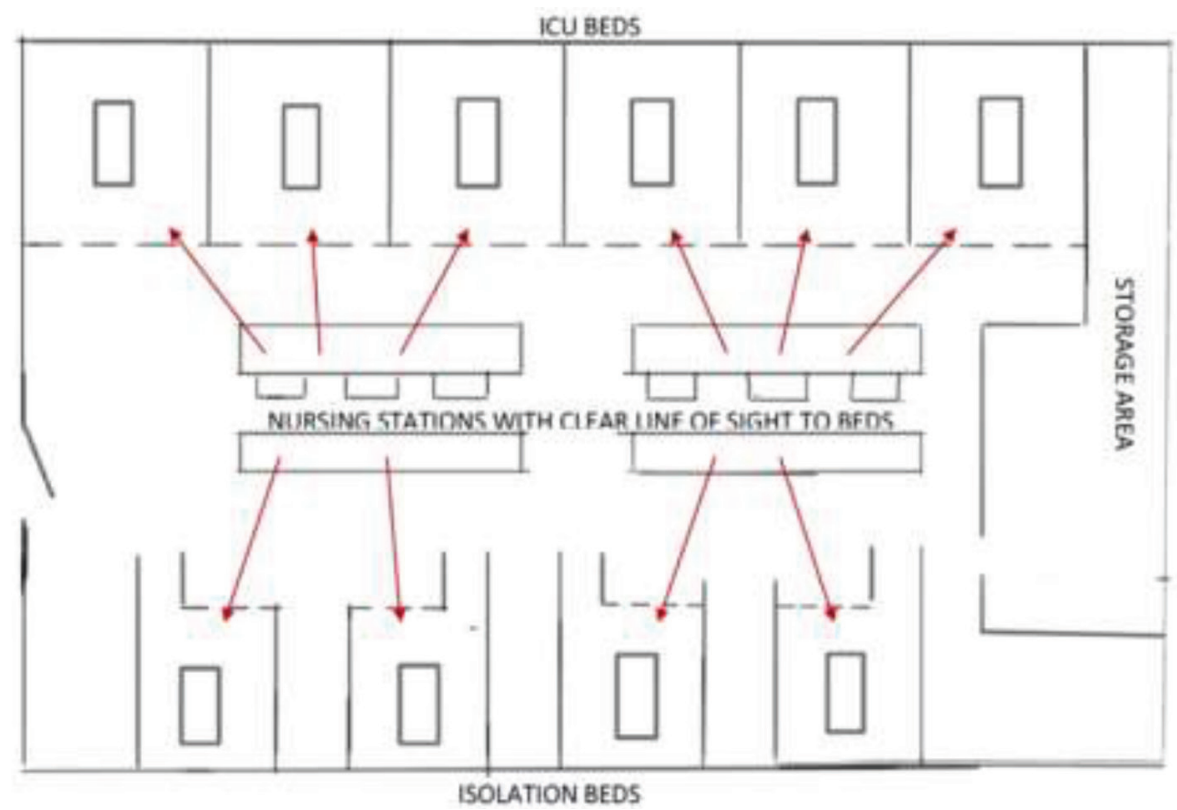

Fig. 1 Organization of a neurocritical care unit (NCCU). 
takes responsibility for all decision making within the ICU, and refers to the admitting physicians only for consultations, or for specialist services. An exhaustive review on the topic is beyond the scope of this article; however, the salient points favoring either strategy are summarized (-Table $\mathbf{1}$ ).

\section{Bed Design and Space}

The total bed strength should be ideally between 8 and 12 , allowing for an area per bed of approximately 100 to $125 \mathrm{ft}^{2}$. In addition, 100 to $150 \%$ extra space should be incorporated in design to accommodate the nursing station, storage, equipment area, duty rooms, and toilets ( - Table 2 ). A requirement exclusive to neurosciences units is the need for 360-degree freedom around the head end of the patient's bed, to facilitate any invasive procedures such as external ventricular drain (EVD) placement, and so forth. It is advisable to designate one or two big rooms to be utilized for patients requiring renal replacement therapy (RRT) and extracorporeal membrane oxygenation (ECMO). Since patient privacy is desirable, partition between two beds can be in the form of standard curtain or aluminum doors. Another important concern is ensuring the availability of beds with a steady increase in the incidence of traumatic brain injury (TBI) being noted worldwide. It is essential to account for emergency admissions as well as beds for elective neurosurgical cases when planning the bed strength of the NCCU.

\section{Visiting Hours in Neurocritical Care Unit}

For neuro-ICUs, more so than other ICUs, the combination of unclear clinical progression and the inability of patients to communicate makes involvement of their families more important. Despite previous suggestions, ${ }^{10}$ many units continue to follow strict visitation policies. The major arguments against open visitation policies seem to be increased stress for the patients, interruptions in provision of care, and exhaustion of the family. Literature suggests the presence of family and friends may actually soothe and reassure the patient, who experiences an unfamiliar and overstimulated environment. ${ }^{11}$ Open visitation may also engender a sense

Table 1 Open versus closed intensive care unit: pros and cons

\begin{tabular}{|l|l|}
\hline Open model & Closed model \\
\hline Less conflict & $\begin{array}{l}\text { Known to be associated with } \\
\text { decreased mortality and re- } \\
\text { duced ICU length of stay }\end{array}$ \\
\hline $\begin{array}{l}\text { Admitting physicians or } \\
\text { surgeons may have better } \\
\text { familiarity with patients }\end{array}$ & $\begin{array}{l}\text { Better coordination of critical } \\
\text { care services }\end{array}$ \\
\hline $\begin{array}{l}\text { Admitting specialists } \\
\text { continue care after ICU } \\
\text { discharge-continuity of } \\
\text { care }\end{array}$ & Cohesive treatment strategy \\
\hline Cost-saving measure & More efficient use of resources \\
\hline Minimizes handovers & $\begin{array}{l}\text { Focused management by } \\
\text { specialists in a critical care } \\
\text { environment }\end{array}$ \\
\hline
\end{tabular}

Abbreviation: ICU, intensive care unit. of trust in the families of patients, helping to create a better working environment.

\section{Caring for Patients with Devastating Brain Injuries}

A problem that remains unique to the neurosciences ICU is that of the otherwise healthy patient, with a devastating injury. Patients with devastating brain injuries usually do not survive, despite optimal management. ${ }^{12}$ Inaccuracies in prognostication may lead to premature withdrawal of organ support, and bias treatment strategies. Care of such patients demands that clinicians make judgments regarding the advisability of continued active therapy in the face of a high risk of undesirable functional outcome. Consensus guidelines recommend using a 72-hour observation period to determine clinical response and delaying decisions regarding withdrawal of therapy in the meantime. ${ }^{13}$ Families of such patients value consistent and compassionate delivery of information by the treating team. The presence of family support specialists may improve communication as well as family satisfaction. ${ }^{14}$ Allowing family presence at the bedside and involving them in care may also be of benefit. Resuscitation of patients with nonsurvivable brain injuries can be draining on resources. Liberal use of resources for such patients may be justified by the possibility of a successful return to an acceptable state of functioning for that individual, or otherwise, the successful transplantation of organs if the patient does not survive. Indian law has not been very clear regarding issues pertaining to withdrawal of life support in the past, with de-escalation and nonescalation of care the only options that could be offered to the kin of patients with nonsurvivable brain injury. The Supreme Court of India (2011) allowed for withdrawal of life support to patients in persistent vegetative states, based upon family requests in the "best interests" of the patient. However, such decisions need to be countersigned by the hospital medical board, and only with permission from the High Court. Regardless of ultimate outcome, aggressive intervention is justified even in scenarios in which death is the most likely outcome, rather than a return to function.

\section{Lighting, Noise, and Sleep Quality}

Approximately $30 \%$ of patients treated in ICUs become either confused or delirious, which may lead to longer ICU and hospital stays. ${ }^{15}$ The link between sleep deprivation and poor outcomes has been well studied, and routine lowering of unit lighting and reduction in overnight activity is to be encouraged. Lowering environmental noise levels may help improve sleep quality as well as improve staff concentration. Measures such as staff sensitization and individualizing alarm volumes and thresholds should be employed. Other measures such as ear plugs may be considered to optimize patient comfort.

\section{Technology in the Neurointensive Care Setting}

The neurointensive care practice relies extensively on recognition of subtle changes in the neurological examination and management of delicate balance between the injured brain and systemic derangements. Findings such as elevated core 
Table 2 List of equipment required for initial setup of a neurocritical care unit

\begin{tabular}{|c|c|c|}
\hline Equipment & Number & Specification \\
\hline \multicolumn{3}{|l|}{ Bedside } \\
\hline Monitor & $1 /$ bed & $\begin{array}{l}\text { Multiparameter monitoring: NIBP, IBP, } \mathrm{SpO}_{2} \text {, ECG, } \\
\text { temperature, and } \mathrm{EtCO}_{2}\end{array}$ \\
\hline Infusion pump & 2/bed & Volumetric \\
\hline Syringe pump & 2/bed & - \\
\hline Head end panel & $1 /$ bed & $\begin{array}{l}\text { With } \mathrm{O}_{2} \text { outlet, vacuum, compressed air outlets, and } \\
\text { procedure light }\end{array}$ \\
\hline ICU bed & - & Electronic control \\
\hline Overbed table & 1/bed & - \\
\hline $\begin{array}{l}\text { Intermittent pneumatic } \\
\text { compression device }\end{array}$ & $1 /$ bed & - \\
\hline \multicolumn{3}{|l|}{ General } \\
\hline Non-invasive ventilators & 2-3 per ICU & With CPAP/BiPAP capability \\
\hline Defibrillator & 2 & $\begin{array}{l}\text { Adult and pediatric paddles, with additional } \\
\text { transcutaneous pacing capability }\end{array}$ \\
\hline ABG machine & 1 & With ABG, electrolyte measurement \\
\hline Resuscitation cart & 2 & $\begin{array}{l}\text { Containing all resuscitation equipment and } \\
\text { medication }\end{array}$ \\
\hline Videolaryngoscope & 1 & \multirow[t]{2}{*}{ For difficult airway scenarios, lavage, etc. } \\
\hline Flexible fiberoptic bronchoscope & $\begin{array}{l}1 \text { each for adult and pediatric } \\
\text { patient }\end{array}$ & \\
\hline Ultrasound machine & 1 & $\begin{array}{l}\text { With all appropriate probes, including capacity for } \\
\text { echocardiography }\end{array}$ \\
\hline Spine board & 2 & - \\
\hline Rigid cervical collars & 4 & - \\
\hline Transcranial Doppler & 1 & For vasospasm screening \\
\hline ETO sterilization unit & 1 & For sterilization of equipment \\
\hline Transport ventilators & 2 & $\begin{array}{l}\text { For transport to and from imaging suite, operating } \\
\text { room (OR), etc. }\end{array}$ \\
\hline EEG monitor & 1 & \\
\hline
\end{tabular}

Abbreviations: ABG, arterial blood gas; BiPAP, bilevel positive airway pressure; CPAP, continuous positive airway pressure; ECG, electrocardiography; $\mathrm{EtCO}_{2}$, end-tidal carbon dioxide; IBP, invasive blood pressure; ICU, intensive care unit; NIBP, noninvasive blood pressure; $\mathrm{SpO}_{2}$, saturation of arterial oxygenation.

body temperatures, hyperglycemia, and hypotension need to be interpreted and managed differently in patients with neurological injuries than in patients admitted to the general ICUs. ${ }^{16}$ Research into state-of-the art technologies, such as multimodality neuromonitoring, biomarkers, and neuroimaging, in neurocritical patients is ongoing. Monitoring modalities such as continuous electroencephalography (cEEG), near infrared spectroscopy (NIRS), transcranial Doppler (TCD), cerebral microdialysis, and jugular venous oximetry, although of limited use in the general ICU setting, assume key roles when used in the setting of neuro-ICUs. ${ }^{17}$ When setting up a neuro-ICU, the importance of acquiring state of the art imaging modalities cannot be overemphasized. Imaging plays a vital role in the identification of potentially salvageable regions of the brain and guiding further management. The most commonly used imaging modalities are computed tomography (CT) and magnetic resonance imaging (MRI). Imaging also plays an important role in the assessment of extent of brain injury, potential for recovery of function, and prognostication. ${ }^{18}$
Another exciting new development in the field of intensive care medicine is the increasing application of machine learning and artificial intelligence. ${ }^{19}$ The myriad monitoring modalities make the neuro-ICU a data-intensive workplace, and the potential benefits of processing such large volumes of data, enabling real-time analysis, and decision making, make machine learning an attractive proposition. In recent times, machine learning algorithms have been successfully used to develop predictive models for sepsis and may eventually be better at predicting adverse events and prognostication than existing clinical models. ${ }^{20}$ Such models are yet to be validated in the NCC setting, but the potential applications, such as predictive models for cerebral vasospasm, seem limitless.

\section{Conclusion}

The management of critically ill neurological patients is complex and is different from general patients admitted to the ICU. This is because of the fact that the pathophysiology of 
the disease process in these patients is complex, and most importantly, the therapeutic targets in neurological patients are different from that in the general patient population.

Conflict of Interest

None declared.

\section{References}

1 Rao SM, Suhasini DT. Organization of intensive care unit and predicting outcome of critical illness. Indian J Anaesth 2003;47(5):328-337

2 Ropper AH. Neurological intensive care. Ann Neurol 1992;32(4):564-569

3 Busl KM, Bleck TP, Varelas PN. Neurocritical care outcomes, research, and technology: a review. JAMA Neurol 2019;76(5):612-618

4 Howard RS, Kullmann DM, Hirsch NP. Admission to neurological intensive care: who, when, and why? J Neurol Neurosurg Psychiatry 2003;74(Suppl 3):iii2-iii9

5 Kramer AH, Zygun DA. Neurocritical care: why does it make a difference? Curr Opin Crit Care 2014;20(2):174-181

6 Kramer AH, Zygun DA. Do neurocritical care units save lives? Measuring the impact of specialized ICUs. Neurocrit Care 2011;14(3):329-333

7 Varelas PN, Conti MM, Spanaki MV, et al. The impact of a neurointensivist-led team on a semiclosed neurosciences intensive care unit. Crit Care Med 2004;32(11):2191-2198

8 Multz AS, Chalfin DB, Samson IM, et al. A "closed" medical intensive care unit (MICU) improves resource utilization when compared with an "open" MICU. Am J Respir Crit Care Med 1998;157(5 Pt 1):1468-1473

9 van der Sluis FJ, Slagt C, Liebman B, Beute J, Mulder JW, Engel AF. The impact of open versus closed format ICU admission practices on the outcome of high risk surgical patients: a cohort analysis. BMC Surg 2011;11:18
10 Berwick DM, Kotagal M. Restricted visiting hours in ICUs: time to change. JAMA 2004;292(6):736-737

11 Rosa RG, Tonietto TF, da Silva DB, et al. ICU Visits Study Group Investigators. Effectiveness and safety of an extended ICU visitation model for delirium prevention: a before and after study. Crit Care Med 2017;45(10):1660-1667

12 Varelas PN, Hacein-Bey L, Schultz L. Conti M, Spanaki MV, Gennarelli TA. Withdrawal of life support in critically ill neurosurgical patients and in-hospital death after discharge from the neurosurgical intensive care unit. Clinical article. J Neurosurg 2009;111(2):396-404

13 Harvey D, Butler J, Groves J, et al. Management of perceived devastating brain injury after hospital admission: a consensus statement from stakeholder professional organizations. $\mathrm{Br} \mathrm{J}$ Anaesth 2018;120(1):138-145

14 Payne S, Burton C, Addington-Hall J. Jones A. End-of-life issues in acute stroke care: a qualitative study of the experiences and preferences of patients and families. Palliat Med 2010;24(2):146-153

15 Girard TD, Pandharipande PP, Ely EW. Delirium in the intensive care unit. Crit Care 2008;12(Suppl 3):S3

16 Kurtz P, Fitts V, Sumer Z, et al. How does care differ for neurological patients admitted to a neurocritical care unit versus a general ICU? Neurocrit Care 2011;15(3):477-480

17 Wartenberg KE, Schmidt JM, Mayer SA. Multimodality monitoring in neurocritical care. Crit Care Clin 2007;23(3):507-538

18 Vespa PM. Imaging and decision-making in neurocritical care. Neurol Clin 2014;32(1):211-224

19 Meyer A, Zverinski D, Pfahringer B, et al. Machine learning for real-time prediction of complications in critical care: a retrospective study. Lancet Respir Med 2018;6(12):905-914

20 Vellido A, Ribas V, Morales C, Ruiz Sanmartín A, Ruiz Rodríguez JC. Machine learning in critical care: state-of-the-art and a sepsis case study. Biomed Eng Online 2018;17(Suppl 1):135 